\title{
A TRANSIÇÃO DE UMA POLÍCIA DE CONTROLE PARA UMA POLÍCIA CIDADÃ
}

\author{
Jorge Luiz Paz Bengochea \\ Luiz Brenner Guimarães \\ Martin Luiz Gomes \\ Sérgio Roberto de Abreu
}

\begin{abstract}
Resumo: Este texto discute as possibilidades de uma polícia diferente em uma sociedade democrática. A concretização dessas possibilidades passa por alguns eixos: mudanças nas políticas de qualificação profissional; programa de modernização; e processos de mudanças estruturais e culturais que discutam questões centrais para a polícia.

Palavras-chave: cidadania; segurança pública; polícia cidadã.

Abstract: This text discusses the possibility of a different kind of police force in a democratic society. This possibility is becoming more concrete by turns: changes in professional qualification policies; a modernization program, and a process of structural and cultural modification that addresses issues of central importance. Key words: citizenship; public safety; citizen police force.
\end{abstract}

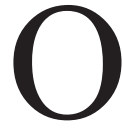
processo de redemocratização do Brasil, a partir da década de 80 , vem provocando nas instituições públicas, em especial nas corporações policiais, transformações decorrentes do questionamento da sociedade brasileira sobre a real função pública que devem assumir diante do Estado Democrático de Direito.

No início dos anos 90, as corporações policiais, cujas práticas históricas foram enrijecidas pelo período ditatorial, começaram um processo de rompimento do modelo histórico do sistema policial, em decorrência das transformações em andamento na sociedade brasileira, em especial o crescimento das práticas democráticas e o fortalecimento da cidadania. $\mathrm{O}$ descompasso entre as mudanças sociais e políticas e a prática policial produz uma crise nas polícias brasileiras, que não é uma crise de dentro da corporação para fora, mas sim o inverso, da relação sociedade-Estado, em conseqüência da falta de sintonia entre o avanço social e a prática policial, ampliada pela ausência de um processo dinâmico e otimizado que faça funcionar um sistema de segurança pública para a realidade brasileira.

Na verdade, há uma reação da sociedade brasileira que indica a necessária mudança no modelo atual, em que a
Justiça é morosa, o sistema prisional é desumano e inócuo e a polícia atual é enfraquecida, fracionada, autoritária e afastada das comunidades, despreparada e obsoleta na sua estrutura, não conseguindo responder às exigências impostas pelo contexto social atual.

É possível ter uma polícia diferente numa sociedade democrática? A concretização dessa possibilidade passa por alguns eixos. Primeiro, por mudanças nas políticas de qualificação profissional, por um programa de modernização e por processos de mudanças estruturais e culturais que discutam questões centrais para a polícia: as relações com a comunidade, contemplando a espacialidade das cidades; a mediação de conflitos do cotidiano como o principal papel de sua atuação; e o instrumental técnico e valorativo do uso da força e da arma de fogo. São eixos fundamentais na revisão da função da polícia.

No modelo tradicional, a força tem sido o primeiro e quase único instrumento de intervenção, sendo usada freqüentemente da forma não profissional, desqualificada e inconseqüente, não poucas vezes à margem da legalidade. É possível, portanto, ter um outro modelo de polícia, desde que passe a centrar sua função na garantia e efetivação dos direitos fundamentais dos cidadãos e na intera- 
ção com a comunidade, estabelecendo a mediação e a negociação como instrumento principal; uma polícia altamente preparada para a eventual utilização da força e para a decisão de usá-la. Tudo isso tendo como base políticas públicas que privilegiem investimentos na qualificação, na modernização e nas mudanças estruturais e culturais adequadas.

No momento em que começa a existir essa transformação política e social e a compreensão da sociedade como um ambiente conflitivo, no qual os problemas da violência e da criminalidade são complexos, a polícia passa a ser demandada para garantir não mais uma ordem pública determinada, mas sim os direitos, como está colocado na Constituição de 88. Neste novo contexto, a ordem pública passa a ser definida também no cotidiano, exigindo uma atuação estatal mediadora dos conflitos e interesses difusos e, muitas vezes, confusos. Por isso, a democracia exige justamente uma função policial protetora de direitos dos cidadãos em um ambiente de conflitos. A ação da polícia ocorre em um campo de incertezas, ou seja, o policial, quando sai para a rua, não sabe o que vai enfrentar diretamente; ele não tem uma ação determinada a fazer e entra num campo de conflitividade social. Isso exige não uma garantia da ordem pública, como na polícia tradicional, sustentada somente nas ações repressivas, pelas quais o ato consiste em reprimir para resolver o problema. O campo da garantia de direitos exige uma ação mais preventiva, porque não tem um ponto determinado e certo para resolver.

\section{UM PROCESSO DE TRANSFORMAÇÃO EM ANDAMENTO DESDE OS ANOS 90}

A violência e a crescente criminalidade estão diluídas por toda a sociedade. Para se chegar à resolução dos problemas, as polícias precisarão fazer uma articulação de ações, compreensão e identificação do seu núcleo, buscando melhores soluções. Ou seja, cada fato que se apresenta hoje para polícia merece um tratamento diferenciado, e esta exigência está estabelecida para a ação da polícia no ambiente democrático. Assim, pode-se perceber que a função policial necessita ser vista, também, como de delicada complexidade e, para ser bem exercida, tornam-se imperativos sua qualificação, o reaparelhamento tecnológico, a atualização das técnicas policiais e, principalmente, sua revisão conceitual.

A sociedade, por sua vez, deve assumir que é uma sociedade complexa, na qual os conflitos acontecem no dia- a-dia e a todo o momento, exigindo da segurança pública ações diferenciadas. Não é possível se fazer hoje um procedimento padrão para o policial no seu trabalho cotidiano. Ele precisa ter a capacidade de ampliar o espaço de decisão nas escolhas das ações e intervenções para cada fato que enfrenta. Então, neste momento, a postura mediadora passa a ser uma função importantíssima na ação da polícia.

\section{O PROBLEMA DA SEGURANÇA PÚBLICA E A INSEGURANÇA COLETIVA: CAUSAS SOCIAIS DA VIOLÊNCIA E DA CRIMINALIDADE}

O grande problema é justamente descrever ou conceituar a segurança pública. Hoje a percepção coletiva considera a segurança pública centrada somente na atividade da polícia e, por mais que se pretenda montar uma polícia cidadã, somente haverá sucesso se for redefinida e ampliada a conceituação da segurança pública.

A segurança pública é um processo sistêmico e otimizado que envolve um conjunto de ações públicas e comunitárias, visando assegurar a proteção do indivíduo e da coletividade e a aplicação da justiça na punição, recuperação e tratamento dos que violam a lei, garantindo direitos e cidadania a todos. Um processo sistêmico porque envolve, num mesmo cenário, um conjunto de conhecimentos e ferramentas de competência dos poderes constituídos e ao alcance da comunidade organizada, interagindo e compartilhando visão, compromissos e objetivos comuns; e otimizado porque depende de decisões rápidas e de resultados imediatos.

A polícia cidadã, sintonizada e apoiada pelos anseios da comunidade, só terá sucesso se estiver voltada para a recuperação de quem ela prende, pois, caso contrário, será simplesmente uma polícia formadora de bandido, quer dizer, ela vai recrutar bandido, vai marginalizar ainda mais. É necessário incluir, nesta análise, todo o sistema de persecução penal e de política social. Esta é a tarefa que precisa ser desenvolvida.

Qual é o modelo que a sociedade quer? É uma polícia "linha dura"? É um Judiciário “duro”, com altas penas? É uma prisão de segurança máxima? Em relação a crianças e adolescentes também medidas de endurecimento das ações repressivas? Existe, na verdade, um aumento da criminalidade em todo o mundo, por razões estruturais, assim como há um senso comum pedindo uma polícia repressiva. A discussão pública e a tendência política brasileira têm apontado como soluções salvadoras o endureci- 
mento da repressão, especialmente quando ocorrem crimes violentos, que assumem amplos espaços na mídia, influenciando a formação da opinião pública.

O cidadão faz a seguinte pergunta: qual é o papel da polícia no momento em que estão em crise o emprego, a família e a escola? Quer dizer, estão em crise as instituições de controle social informal que funcionavam há 20 anos: será que a polícia hoje só pode seguir o modelo de uma polícia, digamos, do tipo tolerância zero? Estaremos condenados a tal? Ou é possível pensar, em um país como o Brasil, outro tipo de policiamento, outra técnica policial, outro tipo de trabalho policial? Porque essa é a grande ignorância vigente na sociedade brasileira: o que significa o trabalho policial?

A questão central é a percepção histórica do fenômeno da insegurança coletiva pela sociedade, a qual não dispõe de um debate profundo e qualificado sobre o tema, ao mesmo tempo em que o próprio poder público carece deste debate, como demonstra a escassez de políticas públicas e as manifestações das autoridades, que trazem uma visão parcial desse fenômeno, ligada apenas a um dos componentes deste sistema, ou seja, a Justiça e a Polícia. A questão da insegurança cresce diante da compreensão de que a Justiça e a Polícia têm problema e, a partir daí, todo o sistema é demandado a achar uma solução para a questão do funcionamento da Justiça e da Polícia. São desconsiderados neste debate os demais setores públicos e sociais que são agentes intervenientes neste sistema.

A Justiça e a Polícia, por si só, provavelmente, são o fator de intervenção de menor capacidade de influenciar nas mudanças das condições desse fenômeno - insegurança pública. Enquanto não se conseguir estabelecer outra forma de percepção desse problema, visualizando o maior número de elementos que o compõem, estaremos obtendo os mesmos resultados de curar uma doença infecciosa, por exemplo, somente com remédio contra a dor, aumentando sucessivamente as doses, tendo, como conseqüência, seu crescimento contínuo.

Ao se considerar o fenômeno em seu conjunto, e não somente em partes limitadas, verificar-se-á que outros modelos e tipos de trabalhos da polícia serão possíveis e necessários. Cabe destacar que vários estudos têm mostrado que aproximadamente $70 \%$ das intervenções policiais não são na área policial, mas sim na social, denominada, aqui na Brigada Militar, de assistência e resolução de pequenos conflitos que não se constituem em infrações penais. Nos $30 \%$ restantes, provavelmente se apontará que a grande maioria das intervenções corresponde a pequenos delitos.
Atualmente a polícia, na sua cultura histórica, só trabalha com um instrumento que é a reação pela força; qualquer conflito e dificuldade são resolvidos pela força. Há muita dificuldade de trabalhar com as situações cuja responsabilidade e culpabilidade não estão bem definidas. Geralmente, em todo o conflito em que a polícia intervém, a tendência é criminalizar a conduta, nem que seja por desacato ou desrespeito, efetivando a solução pelo uso da força e pela prisão. Por conseguinte, outra questão pode ser formulada: numa sociedade democrática, qual o modelo de polícia a ser adotado?

\section{A QUESTÃO POLICIAL NA AGENDA POLÍTICA: O MODELO DE POLÍCIA EM DISCUSSÃO}

A polícia representa o resultado da correlação de forças políticas existente na própria sociedade. No Brasil, a polícia foi criada no século XVIII, para atender a um modelo de sociedade extremamente autocrático, autoritário e dirigido por uma pequena classe dominante. A polícia foi desenvolvida para proteger essa pequena classe dominante, da grande classe de excluídos, sendo que foi nessa perspectiva seu desenvolvimento histórico. Uma polícia para servir de barreira física entre os ditos "bons" e "maus" da sociedade. Uma polícia que precisava somente de vigor físico e da coragem inconseqüente; uma polícia que atuava com grande influência de estigmas e de preconceitos.

Em outras palavras, a questão policial é um item central na agenda de desenvolvimento social e sustentável da sociedade brasileira. O modelo realmente precisa mudar, pois não resolve e não ajuda, porque a técnica policial é superada. Pode-se abordar esta questão, por exemplo, verificando como as polícias começam a se diferenciar pela forma como compreendem a segurança, percebendo a intervenção apenas da ótica da repressão, a ponto de um chefe de polícia vir a público e dizer o seguinte: "se vocês querem resolver o problema da segurança, vocês terminem com o artigo quinto da Constituição Federal". Terminando com o artigo quinto, a polícia vai resolver o problema de insegurança. Qual a influência desta declaração na ação dessa polícia? O que acontece?

É necessário formatar o sistema de segurança no Brasil, um sistema que estabeleça responsabilidades aos governantes, ao Judiciário, ao Ministério Público, ao órgão penitenciário e às polícias, criando ligações técnicas e operacionais e determinando objetivos sociais de prevenção, tratamento e recuperação. Entende-se que o sistema 
de segurança tem de ser sistêmico, rápido, um processo que envolva não só atividades preventivas ou de contenção: precisa ter um início, que é a prevenção, e um final, que é recuperar e tratar os autores do delito, pois, caso contrário, eles voltarão ao crime, e o objetivo é não dar essa oportunidade de reincidência ou aliciamento pelo crime.

Nesse sistema não apenas a polícia é a responsável, o Judiciário, o Ministério Público e a sociedade em geral têm que participar do debate deste tema. É possível ter uma polícia mais eficiente, diferente da atual, que está repartida ao meio: uma trabalha só com a parte investigativa; outra só com a parte pericial; outra só com a parte ostensiva, encasteladas em seus corporativismos. É necessário um trabalho de conjunto e de integração.

Há duas dimensões nesta questão: existe a polícia mais preventiva, que amplia seu campo de atuação, sendo uma polícia das obrigações positivas; e há, também, a polícia mais de controle social, com campo de atuação restrito, voltada para obrigações negativas. A polícia tem centrado suas ações somente nas obrigações negativas: prender, vistoriar, revistar, etc.

O Corpo de Bombeiros, por exemplo, cumpre uma obrigação positiva. A prevenção é a obrigação positiva em que a polícia não avança, e é aí que está o problema. Hoje a polícia não faz mais prevenção, ela faz atendimento de ocorrência. Se estivessem trabalhando em um processo mais amplo e com todas as variáveis, a intervenção da polícia estaria diminuindo e possibilitando um papel mais de interação.

O policial precisará ter uma outra visão de seu objeto de trabalho, uma outra compreensão e, principalmente, ter capacidade e habilidade de estar reconhecendo e compreendendo a diversidade social. Há muita dificuldade de trabalhar com as situações hoje, cuja responsabilidade e culpabilidade não estão bem definidas. Atualmente a polícia, na sua cultura histórica, só trabalha com um instrumento, que é a ação-reação, utilizando-se da força; qualquer conflito deve ser resolvido pela força.

\section{A HISTÓRIA DA BRIGADA MILITAR E A CULTURA PROFISSIONAL VIGENTE}

Existem experiências em algumas unidades da Brigada Militar que são consideradas exemplos de Batalhões verdadeiramente policiais. Nestas unidades, encontra-se a cultura dos "Rambos", havendo uma diferença entre os policiais de fé, os chamados "Kentacky" (guerreiros), ou "quentuchos", e os policiais comuns ou falsos policiais. Os chamados policiais de fé constituem o grupo dos policiais "quentes", corajosos, que vão para a ocorrência enfrentando o bandido, prendendo ou eliminando-o, normalmente, desprovidos dos mínimos cuidados técnicos.

A ação violenta, com uso da força desnecessária e ilegítima, caracteriza-se como requisito para atingir esta conceituação. Nesses locais, até as paredes transmitem a cultura. Quando se transita nos corredores, parece que elas estão dizendo o que fazer para ser o "bom policial", o policial respeitado pelo grupo; isso é reproduzido nas falas, nas expressões, nos elogios, nas punições.

Esse fenômeno da cultura também se reproduz na disseminação de Grupos Especiais, que representam aproximadamente $30 \%$ do efetivo e que são os policiais de verdade; o resto é o resto. Em termos de modelo, o que significam esses policiais especiais? São os super-heróis, os "rambos", em geral sustentados no amadorismo, com pouca capacitação e em ações de violência.

Todo agrupamento policial que não seja um posto policial comunitário precisa contar com um grupo tático especial para responder a chamados que envolvam reféns e enfrentamentos, demandando uma equipe com maior poder de fogo, disciplina e técnica apurada para estes tipos de ocorrências. Porém, jamais uma equipe como esta deveria ser utilizada para abordagens ou patrulhamento, como atualmente muitas unidades assim o fazem, desviando-se das funções para as quais estas equipes especiais foram treinadas e preparadas.

Ao se analisar a história da Brigada, por exemplo, verifica-se que ela foi criada em plena Revolução Farroupilha, dois anos depois de iniciada. Constituía-se, então, em um exército dentro do Estado que participou de vários combates; de todas aquelas revoluções, a Brigada participou, ativamente, como se fosse uma guerra, quer dizer, essa força militar foi formatada conforme focos militares, com pelotão, companhia. Aos poucos, na história, a brigada começou a se transformar em polícia, agregou a guarda civil e, depois, recebeu a missão do policiamento ostensivo fardado, gerando a polícia ostensiva separada da investigação.

Será que não seria possível distinguir, por hipótese, entre uma tradição guerreira e uma militar? Na tradição guerreira, desde 1837 e sucessivamente, segundo a sociologia, o guerreiro tem uma legitimidade social muito grande. A vocação militar foi cunhada a partir de 1967, com a ditadura militar, que realizou uma intervenção em todas as polícias militares e que impôs às Polícias um Comandante 
do Exército, com exceção do Rio Grande do Sul, mas que continua com a Inspeção Geral das Polícias Militares.

Refletir sobre essa hipótese seria importante até para refazer a identidade e a história das polícias militares, pois uma tradição guerreira tem legitimidade social, enquanto uma tradição militar teria menos, pois segue a ótica do inimigo: ou o inimigo é do outro país ou o inimigo é do outro grupo.

Em verdade, perdemos muitas características militares, o padrão do tipo exército, no decorrer dessa transição porque nossa geração entrou na época da ditadura quando já começava o processo de transformação. Nossa polícia sempre foi uma das mais militares entre as brasileiras. Até recentemente no regime disciplinar policial-militar, o servidor, ao cometer uma infração administrativa, não tinha direito à ampla defesa, ao contraditório, ou seja, existia uma autoridade coercitiva. Era possível dizer: "está errado, então vai ser punido", e ele não podia contradizer isso. Então, o modelo de estrutura, de organização, de hierarquia e de disciplina vem do militar e tem um estilo. Por exemplo, na guerra, não pode haver o contraditório, alguém que diga assim: "vai lá e cumpre a missão", eu não posso perguntar por quê. A Brigada Militar foi uma das primeiras no país que mudou esse conceito de disciplina; hoje, o próprio policial militar tem a possibilidade do contraditório e da ampla defesa. Isso foi estabelecido por meio da mudança do Regulamento Disciplinar em agosto de 2001, que eliminou ainda a prisão administrativa e substituiu essa penalidade por suspensão. Por outro lado, voltamos a considerar o seguinte: estamos muito centrados nessa questão da cultura, ou seja, a cultura dominante ainda é o modelo histórico, de polícia tradicional.

O conflito social cria produtos de associação social, ou seja, o conflito gera uma forma de sociabilidade que é superior à anterior, à medida que esta reconhece as diferenças e o conflito, o que é uma forma de impedir a violência dos dois lados.

Tanto o movimento dos proprietários rurais quanto o dos sem-terras, ao se posicionarem num campo de conflito em relação à propriedade da terra, exigem da polícia um comportamento: primeiro, de Estado, ou seja, direcionado a todos os cidadãos, indistintamente; segundo, de mediação do conflito; e, terceiro, de que essa mediação tem que ser tão fina, tão delicada, tão precisa que qualquer deslize tem um significado político brutal. Trata-se de um aprendizado para a sociedade, para os atores sociais, mas o interessante é que há uma percepção, no interior das organizações policiais, de que sua tarefa é com- plexa, delicada e sutil, exigindo uma competência muito maior do que uma ótica penal, exige uma ótica da complexidade.

\section{DILEMAS DO OFÍCIO DE POLÍCIA}

Há outra questão, que é o corporativismo, pois, evidentemente, as instituições policiais são extremamente corporativistas, pelas suas próprias características. Se há um déficit de compreensão do fenômeno segurança e da polícia, o corporativismo apropria-se disso no seu interesse. Então, se a sociedade não consegue compreender a polícia, não consegue provocar as mudanças necessárias.

No Rio Grande do Sul, foi essa a grande disputa do governo Olívio Dutra (1999-2002) tentando realizar mudanças no sistema que mexiam com questões corporativas, como a coordenação única de comando, o registro de ocorrência policial único, o banco de dados integrados, a confecção do Termo Circunstanciado pelas duas organizações policiais, o ensino integrado, ações de inteligência em conjunto, o controle das polícias e a reforma das Corregedorias. Porém, o debate público foi muito medíocre e não houve discussão do mérito dessas ações, sendo que a visibilidade e o senso comum se renderam a muitos mitos corporativos de manutenção de privilégios.

O que está acontecendo no Estado, em 2003? Praticamente, os projetos de integração na área de operações, ensino, inteligência e comando foram abandonados e a fala pública da Secretaria de Justiça e de Segurança é sobre a devolução da autonomia às polícias, de maneira que cada uma faça a sua parte e o faça de maneira separada, cada uma na sua, inclusive com o estímulo ao modelo cultural dos "Rambos", a partir de afirmações reiteradas de que polícia faz a luta do bem contra o mal e que entre o policial e o bandido, o policial deve sempre se sobrepor e vencer de qualquer maneira. Estamos ouvindo falar do seguinte: "agora nós retomamos a auto-estima da polícia". O que é a auto-estima da polícia? É cada um fazer o que quer? São as polícias atuando sem controle, sem necessidade de explicar seus atos, quando a violência ocorre com "supostos criminosos"?

O crescente índice de violência e da criminalidade leva, no âmbito das organizações policiais, a um verdadeiro "jogo de empurra" de responsabilidades. Os dilemas das polícias fundam-se em uma separação: a polícia de investigação diz que o problema é da prevenção; a polícia de prevenção diz que o problema é da investigação; uma está estratificada em relação à outra. Para se ter uma idéia, no 
Rio Grande do Sul, ocorrem em torno de 700 mil delitos por ano: a polícia encaminha para o Ministério Público em torno de 300 mil inquéritos, procedimentos e termos circunstanciados; o Ministério Público consegue denunciar aproximadamente $35 \mathrm{mil}$; o Poder Judiciário consegue condenar, ou fazer um encaminhamento para pena, às vezes até nem é de reclusão, mas é alguma medida social, em torno de 6 a 8 mil.

É necessário investir em uma concepção de polícia cidadã, que é um conceito que se desdobra numa série de dimensões. Por exemplo, a questão da participação comunitária, que inexiste na polícia tradicional, uma vez que ela não foi concebida para isto, é um fator permanente na polícia cidadã, pela aproximação de seus integrantes à população e pelo comprometimento com a segurança pública no local de trabalho, surgindo aí o policiamento comunitário.

No tocante ao uso da arma e da força, a polícia tradicional age mais no impulso de defesa e reação, tendo alto grau de liberdade para agir, muitas vezes, sem critérios bem definidos, enquanto na polícia cidadã é preciso ter um treinamento prático mais apurado, envolvendo emoções e efeitos, que determine padrões limitados de ação que partem de princípios estabelecidos por normas internacionais, acordadas entre países.

Outro fator refere-se à distribuição dos policiais, que, na polícia tradicional, é feita por interferência política, intuição da chefia, dando resposta a uma crise ou em busca de condições financeiras favoráveis à ação policial. Já a polícia cidadã busca distribuir os policiais em bairros, dentro de critérios técnicos e científicos, estabelecendo territórios de responsabilidade e comprometimento da chefia com o estado de segurança. Logicamente que o número de policiais aumentaria, assim como sua integração e seu valor profissional para com a comunidade.

A legislação, por sua vez, privilegia o financeiro (gratificações) e a ascensão dos amigos do poder. Por exemplo, toda a legislação da polícia, hoje, privilegia quem está próximo do poder, quem está na Casa Militar e esta é uma outra discussão que precisa ser feita. Assim, todas as dimensões financeiras e de poder estão associadas a essa possibilidade da polícia tradicional. Agora, a questão da legislação precisaria, para a polícia cidadã, ser voltada para todos, com a valorização de quem desempenha a atividade-fim, que é uma coisa que não consegue reverter esse processo; hoje, o policial que está na atividade-fim ganha menos, tem ascensão mais dificultada e não possui capacidade de agregação política. A polícia tradicional tam- bém tem baixos salários, com um distanciamento elevado entre o primeiro e o último nível, e a polícia cidadã precisa ter um salário razoável, com pouco distanciamento entre os níveis hierárquicos, como, por exemplo, a polícia rodoviária federal.

Um soldado, um policial patrulheiro - até esse nome soldado não é adequado - tinha que ser substituído por outro qualificativo que melhor identificasse a função, como: patrulheiro, oficial de rua, oficial de polícia, etc. A presença dos policiais na rua sob a ótica da polícia tradicional está basicamente onde circula as classes alta e média.

Uma polícia cidadã tem de estar presente em todos os bairros, na forma real ou potencial, atuando com ênfase na prevenção dos delitos, especialmente naqueles locais de maior vulnerabilidade social e de elevado nível de conflitualidade. É claro que isso é muito complexo e depende da visão de mundo. Tudo isso proporciona um campo profundo para discussões, porque não são coisas que podem ser resolvidas com uma pequena conversa, numa entrevista com curto tempo de duração. Entretanto, como elemento para futuro debate, pode-se aprofundar elementos dessa visão do mundo. A polícia tradicional parte do princípio de que existe dois mundos: o do bem e o do mal. A polícia de controle (tradicional) parte com essa visão, ou seja, o traficante é o traficante e o cidadão é o cidadão, por exemplo.

\section{CONTROLE SOCIAL LEGÍTIMO DE UMA POLÍCIA CIDADÃ}

O controle social de uma polícia cidadã é aquele que sai da sociedade e entra para a polícia. É uma visão completamente diferente da atualmente existente. Para a Polícia Civil o assunto é mais temido do que para a Polícia Militar. O próprio Ministério Público, que tem como uma de suas responsabilidades o controle da polícia, afirma que essa tarefa é difícil. Para a sociedade, que carece de segurança pública, o peso é maior. Há muito tempo a sociedade está afastada dessa discussão.

Somente nos últimos anos, com casos de violência mais graves, iniciou-se uma discussão nacional na qual apareceram debates sobre a participação da sociedade, polícia comunitária, controles sociais. Os Estados brasileiros se organizaram com Ouvidorias e as organizações reformularam as corregedorias policiais. A sociedade democrática brasileira sentiu a necessidade de discutir o tema, e os legisladores aprovaram o princípio participativo de 
segurança pública na Constituição, ao instituírem que a "segurança pública é um dever do Estado e responsabilidade de todos". Portanto, o controle social da polícia é uma garantia constitucional. A polícia, que tem legalmente o dever do uso da força e das armas, necessita de um olhar controlador pela sociedade. Isso é o início da passagem da polícia que controla para a polícia que é controlada.

É possível imaginar como deveria ser a transformação de uma polícia que controla para uma polícia cidadã, em alguns pontos de sua estrutura e funcionamento: a logística atual da polícia de controle é pesada, enquanto a da polícia cidadã é leve; a formação da polícia de controle é boa, mas é etnocêntrica, não integrada, e a da polícia cidadã é mais interativa, unificada; a disciplina na polícia de controle é autoritária, centrada nas atitudes inadequadas, na apresentação, na uniformização de policiais, enquanto na polícia cidadã deve estar baseada na ampla defesa do policial, na possibilidade de ter o contraditório e também centrada na conduta operacional asséptica à corrupção, por exemplo, a hierarquia, na primeira, tem muitos graus (soldado, cabo, sargento, subtenente, tenente, capitão, major, tenente-coronel, coronel), o que, na polícia cidadã, precisa ser adaptado, ou seja, deveria ter os níveis adequados à ação que produz.

A polícia atual prende para investigar, enquanto a polícia cidadã deveria investigar para prender, seria uma polícia mais inteligente. A polícia de controle usa técnicas de troca de favores, de alcagüete, com dinheiro para pagar os informantes, e a polícia cidadã usa outra tecnologia, como a escuta judicial, técnicas de prova científicas (DNA), que possibilitam um avanço muito forte na perícia. Os bancos de dados são separados na atual organização policial. A polícia cidadã teria um banco unificado ou bancos inter-relacionados. Também sobre essa questão dos bancos de dados e a produção das estatísticas, na polícia de controle o uso das informações segue a regra do segredo, de não repassar informações, de deixar escondido, de não ter a transparência. Já a polícia cidadã colocaria a base de dados disponível, socializada, permitindo o acesso de estudiosos e pesquisadores. Essa cultura do segredo precisa ser redefinida e instalada nas organizações a fim de não representar uma dimensão de poder.

Na polícia de controle, a polícia é o poder, enquanto na polícia cidadã, a polícia é serviço. As políticas de segurança pública, na polícia de controle, são isoladas e o político não interfere. Portanto, a concepção de que só a polícia tem que resolver a política de segurança pública e que esse assunto é de responsabilidade dos técnicos deve perder força para uma nova estratégia, em que a comunidade cada vez mais assuma sua participação, discutindo o assunto, apropriando-se e exercendo o controle social sobre as ações públicas de segurança e das políticas de segurança pública.

A questão dos bombeiros, atualmente, está mais atrelada ao corporativismo do que à funcionalidade administrativa, voltada totalmente para a logística. Os bombeiros integram, no Rio Grande do Sul, a Polícia Militar, não tendo autonomia financeira e administrativa. Eles acabam fazendo parte dessa logística que precisa ter poder. Já numa estrutura de polícia cidadã, esses bombeiros seriam vinculados à Defesa Civil.

A presença dos policiais, na polícia de controle, está basicamente onde circula a classe média; as viaturas ficam paradas em cruzamentos de grande circulação, para poder chamar a atenção da sociedade que mais tem repercussão sobre a questão da mídia. A polícia cidadã deveria estar mais presente nos locais de vulnerabilidade social.

A grande dificuldade da polícia cidadã é a seguinte: numa ocorrência de violência policial, o próprio policial tem dificuldade de entender porquê isso está acontecendo; essas são questões que deveriam ser desdobradas, mas pode-se afirmar que a polícia, numa sociedade democrática, é uma instituição que não será o centro do processo da segurança, mas sim um ente complementar a uma série de outras ações, devendo ser extremamente técnica porque precisa reconhecer e compreender a diversidade e conviver com todo esse processo de diversidade social. $\mathrm{Na}$ concepção de uma polícia cidadã, um soldado, um policial, deveria ser patrulheiro, oficial de rua, oficial de polícia.

Existe a necessidade do administrador público ter a coragem de fazer com que haja interferência no processo, através da reativação da Corregedoria Externa, das Ouvidorias, de um processo de discussão, que possibilite às pessoas se queixarem, falarem e terem respaldo, que não seja um simulacro ou represente insegurança. Atualmente, o controle das polícias e dos demais órgãos do sistema penal é muito frágil, limitando-se às Corregedorias internas, sem que haja qualquer preocupação de ser criado um espaço que permita e encoraje as pessoas a apontar as irregularidades da prestação do serviço na área da segurança pública. O modelo atual é, ainda, predominantemente intimidatório e carregado de proteção corporativa. Desejamos reafirmar: na polícia cidadã, a polícia é serviço. 


\section{OS GRUPOS EM VULNERABILIDADE SOCIAL E A POLÍCIA}

Todas as políticas públicas devem ser direcionadas a grupos mais vulneráveis, como é o caso do jovem, do negro, do deficiente físico, das mulheres, dos índios e dos profissionais do sexo. Na formação da polícia deveria haver espaço para se tratar desses grupos, pois, pela sua vulnerabilidade, são os mais visados pela polícia.

No Rio Grande do Sul, iniciou-se um trabalho, com a formação integrada de policiais, em que algumas oficinas tratavam do problema com instrutores específicos e militantes desses movimentos. No início, não foi fácil o trabalho, pois rompia a cultura existente, mas, em seguida, pôde-se perceber alguns avanços, como é o caso da maneira da polícia denominar determinados grupos segregados pela sociedade.

A surpresa foi quando estávamos interessados em fazer uma pesquisa por palavra de ocorrências registradas e percebemos que os termos "homossexual" e "bicha" haviam sido trocados por "profissional do sexo". Isso é um início do processo de reconhecimento e de qualificação dos policiais em relação aos grupos mais vulneráveis. É preciso retirar o conceito que a polícia tem sobre o "elemento suspeito". O jovem e os grupos vulneráveis não podem mais sofrer essa discriminação e violência por parte da polícia. A mudança começa na formação da polícia e na busca de políticas sociais de atendimento e geração de emprego e renda. Essa reformulação interna da polícia depende também dos movimentos da sociedade e, por isso, o controle social não é um controle da polícia sobre a sociedade, mas tem que ser um controle da sociedade sobre a polícia. O jovem não pode mais ser tratado como um caso de polícia.

Por que o policial não trata melhor o jovem? Ele não trata melhor porque o modelo policial é autoritário. O jovem possui o espírito de querer respostas rápidas, objetivas e tem o "critério da verdade pela argumentação". Para o policial, acostumado com o "critério da autoridade", quando aborda um jovem e esse quer saber "porquê?", isso pode ser entendido como uma ofensa. O policial necessita cada vez mais se afastar do modelo autoritário, passando para uma ação mais fundamentada na argumentação, na mediação e na resolução de conflitos. Para alguns segmentos da polícia, isso é confundido com quebra da disciplina e da hierarquia. A passagem da identidade da Polícia Militar para a polícia policial ainda levará alguns anos. Esse resíduo cultural de disciplina e hierarquia militar ten- derá a ser transformado em instância mais organizativa do que concepção ideológica de ação policial. Esse salto é a passagem para uma polícia mais inteligente, mais democrática e mais comunitária. No passado a Brigada teve, por um período da sua história, a denominação de Brigada Policial. Talvez possamos começar a mudança dessa organização trocando seu nome, porque nem o exército é militar, é exército brasileiro. No entanto, a mudança é mais profunda, uma vez que está em disputa a cultura de uma forma de agir.

\section{A POLÍCIA NOS CONFLITOS AGRÁRIOS}

A sobreposição da repressão em vez da negociação intermediada e do entendimento legal na ação policial está presente não somente na atuação dirigida aos jovens, mas também nos conflitos agrários. Essa forma de ação da polícia nos assentamentos ou nos conflitos agrários, na qual a Polícia Militar tem uma autoridade real, pode resultar em violência, em excesso de poder, se não forem previamente planejadas suas ações em conjunto com as autoridades civis envolvidas. Tal situação está muito ligada ao próprio conceito do que é ordem pública hoje no Brasil. Entretanto, quem é que determina esse conceito de ordem pública?

Tivemos a experiência de trabalhar em nove invasões de terra e em três conflitos envolvendo indígenas no norte do Estado. Nestas ocasiões, sempre existiu por parte do Comando da Força Policial a preocupação de não incorrer nos erros da desocupação da Fazenda Santa Elmira, propriedade de 2.200 hectares, entre os municípios de Salto do Jacuí e Tupanciretã. Nesta desocupação, em março de 1989, numa operação de guerra, ocorreu um confronto armado e corporal, que terminou com dezessete colonos e quatro policiais militares feridos a bala, além de dezenas de feridos leves e vinte e um colonos presos. A relação dos direitos humanos e dos aspectos sociais e políticos que envolvem uma ocupação de terra começou a influenciar as decisões dos comandos, tornando as negociações mais importantes que a ação direta de desocupação, e o cumprimento de decisão judicial deveria buscar a garantia de segurança de todos os envolvidos, entendendo que cada parte tinha suas razões.

Ocorreram situações, por exemplo, em que tivemos de intervir retirando policiais que estavam comendo churrasco com carne doada pelos proprietários da fazenda envolvidos no conflito, quando a força policial deveria estar isenta para poder cumprir suas tarefas. E ocorreu uma reação 
muito grande por parte dos fazendeiros, pois não esperavam aquela atitude porque sempre tinham a Polícia Militar para proteger sua fazenda, e a medida adotada teve grande repercussão.

Houve, também, a preocupação de colocar, nas negociações e no cenário que envolve esses fatos, o Judiciário e o Ministério Público como partes ativas da resolução. A Justiça para dar o suporte legal e o Ministério Público para as questões que envolvessem crianças e adolescentes, porque na Fazenda Santa Elmira crianças e adolescentes foram usados como proteção diante da ação policial. Essa preocupação teve uma repercussão positiva para a solução pacífica das ocupações que ocorreram a partir daí.

Quando há a presença do índio, em conflitos de terra, a situação é ainda mais complexa. Nesses casos, é primordial o envolvimento da Justiça Federal, do Ministério Público Federal e da Funai para estabelecer uma negociação. Numa determinada ocasião, na Reserva de Nonoai, tivemos que providenciar um policial que falasse a língua nativa "Kaigangue" para estabelecer o diálogo com o cacique e os índios.

O MST, por exemplo, não é visto pelo Estado, pela administração, como uma questão de disputa de direitos à propriedade da terra, mas sim como um conceito de ordem pública, em que o MST é inimigo. Em setembro, foi realizado na Av. Borges de Medeiros, no Centro de Porto Alegre, um ato devido à morte do soldado Valdeci, num conflito que ocorreu na Praça da Matriz. Entretanto, quem pensou aquele ato o está realizando em razão de todo o conflito hoje existente, para tentar dar legitimidade a uma ação mais violenta da corporação; quem fez aquele ato está pensando em resguardar a corporação, num modelo de enfrentamento e tradição.

Então, esse conceito é determinado e, nessa disputa, se fala da violência do MST na marcha, mas quem é que está provocando a violência? Os atos violentos são todos do grupo ruralista. As inspeções que deveriam ser feitas no campo foram proibidas de ser e, quanto à desapropriação dessa fazenda em questão, o Supremo deu ganho de causa e mandado de segurança, pois, por um ato formal, não houve a notificação da vistoria. Por que não houve a notificação da vistoria? Porque o proprietário fugiu e, além disso, foram erguidas barreiras para impedir que a equipe do Incra chegasse ali.

No caso dos conflitos agrários, existem no Brasil experiências lamentáveis de ação de policiais militares, mas seria possível ter um outro tipo de ação de policiais militares em ocorrências, inclusive de retirada de pessoas, condenadas pela Justiça por esbulho possessório, ou por entrave de circulação em estradas federais. Reconhecemos que nessas situações em que o Judiciário emite uma decisão, cabe ao governo do Estado cumpri-la e isso é função das polícias, em especial da militar, mas poderia haver um outro tipo de ação.

No centro disso está a compreensão desse fenômeno, porque uma coisa é trabalhar com uma ocorrência que está eminentemente tipificada como crime - um assalto, um arrombamento, um seqüestro -, outra coisa é estar desenvolvendo uma intervenção que envolve movimentos sociais de todas as formas - a greve, qualquer movimento que tende a pressionar, por exemplo, e o MST é um movimento social. Qual é a grande diferença? Se compreendemos que esse movimento está sendo feito e o analisarmos numa perspectiva criminalizante, ou seja, é um crime, vamos reagir contra esse movimento da mesma forma que agimos contra um assalto a supermercado que precisa ser reprimido. Entretanto, não é a mesma coisa.

\section{A CARÊNCIA DE TÉCNICAS POLICIAIS INOVADORAS}

Quais são as técnicas policiais de prevenção: quanto mais visível possível melhor? O que avançou em termos de técnicas de prevenção na polícia ostensiva? Avançou muito pouco, a polícia não está preparada, organizada. Outra discussão é a falta de democratização da polícia, pois ela não entrou nesse processo de democratização, se fechou e não funciona.

Poucos policiais dominam as tecnologias de informação mais sofisticadas e necessárias, como o georreferenciamento, o cruzamento de dados. O caso da digitalização das impressões digitais é exemplar: hoje, para procurar um criminoso, a polícia precisa consultar milhares de fichas. No ano passado começou o processo de digitalização, ou seja, já têm em torno de 50 ou 100 mil pessoas que passaram pela polícia e agora, por meio da consulta no terminal, é possível saber, pela impressão digital, a situação policial e criminal da pessoa. Nossos controles são ainda muito rudimentares; é um processo caótico e precisa de grande investimento.

Quando acontece um crime, a força policial precisa estar completa no local: perito, investigador e policiamento ostensivo para fazer o isolamento do local. Isso não se verifica no Brasil, além de freqüentemente ocorrerem brigas corporativas nesses locais. A técnica da perícia é muito ineficiente: por exemplo, de cada dez perícias que são 
feitas em Porto Alegre, em torno de 4 a 5 são erradas porque a polícia não sabe chamar o perito e/ou apontar suas reais necessidades para a investigação. E a perícia é fundamental para a investigação criminal e a produção das provas.

O policial de rua, o policial de policiamento, é o mesmo policial, mas a técnica, a instrução do policial de rua não é a mesma de uma operação específica, tanto é que a utilização é da tropa especial, que faz realmente a desocupação em caso de necessidade. $\mathrm{O}$ isolamento é feito no local com os policiais de rua.

\section{A CONSTRUÇÃo DE UMA POLÍCIA CIDADÃ}

A polícia cidadã é uma concepção de polícia que problematiza a segurança, discute sua complexidade e divide responsabilidades. O consumo e o tráfico da droga são práticas comuns de todas as classes sociais e, portanto, é falsa a divisão entre o bem e o mal. Não pode-se dizer: "olha, eu estou do lado dos de bem", como se os homens de bem não fossem o lado mal da sociedade também, como se a sociedade tivesse isolado os de bem de um lado e os de mal do outro. A sociedade é complexa, e a ilegalidade ou infração é perpassada por todas as classes e os níveis.

Na preparação de uma aula para Guarda Municipal, o capitão afirmou: "não, a gente faz abordagem e hoje a gente tem que abordar também os caras de colarinho, de gravata, eles assaltam bancos também”. Então, o que ele quer dizer com isso? Ele quer dizer que tem uma cultura que precisa ser mudada, ou seja, que bandido não é só o cara que está mal arrumado, o negro, o homossexual ou travesti ou o cara de vila ou o que está com a roupa suja. Agora começa a desenvolver a compreensão de que também o cara de gravata pode assaltar um banco; e aí existe uma outra concepção, pois a visão muito fragmentada da polícia não resolve e nunca resolverá os problemas. É preciso ter interdisciplinaridade, multiagencialidade, visão solidária de responsabilidades, bem como visão da própria competência das polícias, que precisam ser solidárias e compartilhadas e não divididas.

No Rio Grande do Sul, o sistema policial avançou muito até o presente momento. A adoção do boletim de ocorrências único para as polícias Civil e Militar, expresso ora como termo circunstanciado ou registro de ocorrências, é o ponto fundamental da integração das polícias, possibilitando atendimento mais imediato ao cidadão, aperfeiçoando a coleta de informações no local do crime, per- mitindo medidas periciais com maior dinamismo e, principalmente, no tocante às ocorrências de menor potencial ofensivo, o encaminhamento direto do local do conflito para o Poder Judiciário, onde será resolvido terminantemente. Este procedimento atende de forma eficaz a um dos maiores problemas da atualidade quando o cidadão está diante de um conflito: o acesso à Justiça, de forma célere, imediata e imparcial, sem intermediações burocráticas. Até então, o policial tinha o processo de apenas conduzir e não interagia com o próprio delito, isentava-se de qualquer responsabilidade de interferência, inclusive não conhecia essa relação porque não tinha capacidade nem competência para tanto. A instituição do termo circunstanciado não consiste simplesmente num formulário a ser preenchido. Nele, está subjacente um novo conceito de polícia, em que o policial deve estar preparado para entender os conflitos das pessoas, aceitar que existam esses conflitos, que são inerentes à sociedade e que ele tem que tomar uma posição central em que ele não pesa nem para A nem para B, compreendendo as posições do A e as do $\mathrm{B}$, para poder encaminhar aquele conflito à Justiça. Precisa, então, possuir essa habilidade de organização do espaço, da composição do conflito, para que possa ser encaminhado.

Além disso, na concepção da polícia tradicional, há uma idéia de que ela é final, ou seja, de que prendeu, terminou o criminoso, não tem mais aquele crime. Na verdade, a polícia é um elemento inicial no processo de persecução criminal. Quando um policial efetua uma prisão, o infrator será submetido ao processo criminal e, tendo ele obtido um habeas corpus ou, no caso de flagrante, sua prisão não for homologada, ele recuperará sua liberdade. Se ele vier a cometer outro delito, a função da polícia é voltar a prendê-lo, fazer novas provas para que ele retorne ao sistema prisional. Isto faz parte da função policial, não é estanque a sua atividade, irá sempre se repetir como parte da atividade policial, sendo por isso um meio e não o fim desse processo. A sociedade coloca a polícia como determinante do fim do processo, quando na realidade atual é o início do processo de persecução criminal, em que a decisão final - a aplicação da lei - será feita pelo Juiz de Direito.

No contexto do controle social e da constituição de uma polícia cidadã, os mecanismos de acesso dos cidadãos à polícia através de Ouvidorias são importantes para a transparência das práticas policiais. Existe a necessidade do administrador público ter a coragem de fazer com que haja participação dos cidadãos no processo, por meio da reativação, por exemplo, da Corregedoria externa, das Ouvi- 
dorias, de um processo de discussão que possibilite às pessoas direcionarem suas denúncias, questionamentos e sugestões. Atualmente, o controle das polícias e dos demais órgãos do sistema penal é muito frágil, limitando-se às Corregedorias internas, sem que haja qualquer preocupação de se criar um espaço que permita e encoraje as pessoas a apontar as irregularidades da prestação do serviço na área da segurança pública. O modelo atual é, ainda predominantemente intimidatório e carregado de proteção corporativa.

Parte do processo de compreensão dos policiais é o reconhecimento de que intervir no movimento social não é o mesmo que estar intervindo na criminalidade. A partir desse entendimento, a polícia terá uma perspectiva de que ela precisa reestabelecer a ordem e cumprir a ordem judicial, mas tem de preservar as pessoas que estão ali e reconhecer que o movimento possui certa legitimidade, fazendo o processo de mediação. Se fizermos isto, estaremos encaminhando soluções que trarão menos processos de enfrentamento ou de violência.

Com este objetivo, passou-se para um procedimento de negociação e mediação do conflito com os movimentos sociais. Os processos de mediação exigem maior tempo para sua implementação. É possível uma polícia tratar da questão dos movimentos sociais de uma forma diferente, e nisso, a Brigada Militar agregou muito nos quatro últimos anos.

Há experiências promissoras e apropriadas na polícia. A Brigada Militar começou um processo interno de formação, tanto operacional como técnico, que sedimentou conteúdos, para além de mudanças de governos políticos. Do ponto de vista da democracia, é importante no sentido que estamos conseguindo verificar que existe a constituição de um corpo de funcionários do Estado e não apenas de funcionários de Governo. Hoje a Brigada tem como padrão de referência, na ação policial dos movimentos sociais, o acompanhamento, a negociação e a mediação. Existe, ainda, envolvimento da Justiça, do Ministério Público e de todos os outros setores, para que eles também participem na resolução do problema. Os conceitos estão mudando.

O grande desafio colocado no processo de democratização dos países da América Latina, hoje, quanto às Organizações Policiais, é a questão da função da polícia, do conceito de polícia. Essa definição é manifestada pela transposição da polícia tradicional, voltada exclusivamente para uma ordem pública predeterminada e estabelecida pelo poder dominante, para uma polícia cidadã, direcio- nada para efetivação e garantia dos direitos humanos fundamentais de todos os cidadãos.

A relação com a comunidade precisa ser trabalhada em todas as variáveis, trabalhar a mobilização comunitária, outros processos de intervenções nas áreas sociais que venham interferir na melhoria da vida em coletividade. A própria gestão e o sistema precisam ser sincronizados, quer dizer, não se compreende mais, no atual modelo, que as polícias tenham um banco de dados cada uma e que um não conversa com o outro e não conseguem se complementar.

Outro obstáculo consiste na inexistência de áreas de responsabilidades que sejam coincidentes para todos os organismos do sistema de persecução penal e também para a divisão política e comunitária dos municípios. Essa deficiência, até aqui, tem contribuído para que não haja dados estatísticos, indicadores e índices de conjunto em relação a um espaço territorial, agregando as informações produzidas por todos os subsistemas. Contribui, também, para a ausência de implantação de planos de atividades em conjunto, bem como para a falta de aproximação desses órgãos com suas comunidades locais.

Deve-se discutir, primeiramente, a questão dos problemas do sistema, o ciclo de polícia, o inquérito policial, a inteligência única e a formação adequada e integrada. A proposta de que a guarda municipal será uma solução imediata não se sustenta sem abordagem dos problemas mencionados anteriormente e somente reproduzirá o modelo que está aí, consistindo em uma lógica de resolver o fenômeno da insegurança pública somente por meio de medidas quantitativas. Precisamos intervir nos problemas do sistema para depois discutir a polícia municipal.

Defendemos a construção de um aparelho policial completo, que tenha suas divisões investigativa, pericial e ostensiva, além de forças especiais para atuar somente nos momentos de crise; também uma polícia municipal para aumentar os efetivos de patrulhamento comunitário e determinar responsabilidades ao Executivo municipal na segurança de sua comunidade.

A polícia estadual, do jeito que está retratada, só incentiva o corporativismo, a corrupção, a omissão, a falta de responsabilidade com o local de trabalho e as dificuldades na elucidação dos ilícitos. Temos uma polícia investigativa que, apesar de trabalhar a civil, está sendo empregada ostensivamente com fardamento preto e viaturas padronizadas, enquanto a outra, que deveria ser preventiva, continua atuando dentro de estratégias militares e ações puramente repressivas. 
Para o país, novos conceitos de sistema de segurança devem ser revistos e escritos, envolvendo o Judiciário no recebimento das ocorrências, no trato imediato e menos burocrático dos ilícitos, nos processuais, no julgamento, na aplicação e execução da pena, no acompanhamento dos benefícios legais e na recuperação social dos apenados. $\mathrm{O}$ inquérito policial tem de ser extinto, pois há necessidade de um novo instrumento mais rápido, desburocratizado e eficaz realizado pela Justiça e não mais pela polícia, a qual ficará responsável pelo levantamento das provas, preocupando-se com a investigação e a elucidação dos delitos. As atividades de polícia devem ser compartilhadas e estruturadas em ciclo único de intervenção e prestação de serviço.

\section{AS MUDANÇAS NA FORMAÇÃO POLICIAL E AS UNIVERSIDADES}

Historicamente, verifica-se que as Secretarias de Segurança são ocupadas por juristas positivistas ou militares das Forças Armadas, que trazem seus conceitos para dentro desse processo. A abordagem somente através da ideologia positivista ou pela ideologia militarizada é insuficiente e não apresenta soluções eficientes.

Existe um deficit, uma lacuna, uma ausência de discussão, na sociedade brasileira, no Estado, na sociedade civil, no setor empresarial, em todos os setores, sobre a questão do sistema de segurança pública que esteja de acordo com a sociedade brasileira e que estabeleça os processos de relacionamento entre as instituições e seus objetivos sociais, o papel do Judiciário, do Ministério Público e das penitenciárias, e que modelo de polícia a sociedade quer construir para a segurança de todos os cidadãos. Neste contexto, o papel das universidades públicas é fundamental.

O policial precisa ter uma formação acadêmica multidisciplinar, em que as áreas humanísticas, jurídicas, administrativas e técnicas-profissionais sejam abordadas de forma interdisciplinar e com temas fundamentais de cada uma delas, ensejando a transversalidade do currículo. $\mathrm{O}$ estado da arte de cada área deve ser enfocado sob a ótica do ofício de polícia. O currículo de formação e qualificação dos policiais deve proporcionar sua autonomia para poder enfrentar os conflitos e buscar a melhor solução.

O policial precisa ter uma formação própria, pois apenas o Direito não forma um policial, a Administração não forma um policial, a Sociologia não forma um policial; ou seja, o policial, pela complexidade da sua atividade e importância das atividades de prevenção, teria que ter todo um processo de conteúdo próprio.

Há uma questão polêmica: no momento em que a Brigada Militar adotou como condição essencial para ingresso no curso de oficial o bacharelado em Direito, em 1997, decisão apoiada por $99 \%$ dos brigadianos, alguns consideraram que houve um retrocesso na nossa caminhada para uma polícia adequada aos momentos atuais e futuros. Essa opinião provavelmente não representa $1 \%$ dos policiais militares. Havia o entendimento de que a única forma de se manter um processo isonômico econômico com os delegados de Polícia e as carreiras jurídicas era ter o Direito como exigência de ingresso. Essa polêmica permanece até hoje.

Houve todo um movimento de transformação na Brigada Militar. Nesse sentido, possuímos uma visão da importância da criação do Instituto de Pesquisa. Começamos a trabalhar um pouco a epistemologia da questão da violência, uma maior aproximação com a universidade, sair do casulo, ter uma visão fora do etnocentrismo e buscar a constituição de uma massa crítica que pudesse fazer um agregado de uma outra polícia que sempre queríamos que existisse.

O policial é aquele que deve estar preparado para resolver a ocorrência sozinho, pois não há um superior para ajudá-lo naquele momento. Para ele estar preparado, tem que haver um investimento muito grande do Estado para dar capacitação adequada em qualquer situação. Para haver esse trabalho, tem que existir investimento na polícia.

Atualmente, no meio acadêmico, não há o domínio do conceito de polícia, porque a polícia sempre foi percebida por todos como uma mão-de-obra não especializada, uma atividade extremamente fácil. Por que ela é uma atividade extremamente fácil? Porque, segundo tal idéia, ela é uma atividade que precisa somente de vigor físico e coragem inconseqüente. Então, não necessita de inteligência, de intelectualidade, estar estudando isso; precisa somente ser uma barreira física para separar o bom do ruim e assim ela foi construída. Por conseqüência, segundo esta concepção, de que precisaria a polícia? A polícia precisaria ter vigor físico e coragem inconseqüente para pegar alguém a unha e servir mesmo como um robozinho, ou seja, separar o bem do mal.

Precisamos trabalhar essa idéia de pensar a polícia enquanto uma atividade complexa e de difícil execução. É necessário que ela seja pensada, também, de dentro para fora, inclusive levantando os problemas e colocando as coisas como são mesmo. Isso é muito importante no sen- 
tido de se construir, junto com a universidade, um debate profundo e sério.

A convicção predominante no grupo é a de que as mudanças na polícia só podem sair de dentro da polícia, em conjunto com os campos mais avançados, que são os pesquisadores e especialistas desta área do conhecimento. Então, esse processo de estimulação é uma função da universidade, que instiga, propõe e questiona. A própria polícia tem que disponibilizar as informações e abrir suas organizações, por mais conservadores que sejam.

Ocorre, atualmente, um processo de se inserir no campo universitário a discussão da complexidade da segurança pública e da gestão através da polícia. Essa é a nossa encruzilhada, nesse momento: a compreensão do fenômeno, ou seja, quem dirige a administração pública, para desenvolver políticas de segurança, não compreende o fenômeno.

O problema todo é o seguinte: há um deficit enorme de compreensão sobre esse fenômeno para que se possa formar uma massa crítica para realizar a intervenção política construindo políticas de segurança, pois a abordagem somente pela ideologia positivista ou pela ideologia militarizada é insuficiente e não apresenta perspectivas de solução. Neste contexto, o papel da universidade é fundamental, como tem sido em outras políticas. Todo conceito que é construído pela problematização é mais perene, articulado e dinâmico e tende a ser um conceito da sociedade moderna que também acompanha esses princípios.
O grande desafio colocado no processo de democratização dos países da América Latina, hoje, quanto às organizações policiais, é a questão da função da polícia, do conceito de polícia. Esta definição é manifestada pela transposição da polícia tradicional, voltada exclusivamente a uma ordem pública predeterminada e estabelecida pelo poder dominante, para uma polícia cidadã, direcionada para efetivação e garantias dos direitos humanos fundamentais de todos os cidadãos.

\section{NOTA}

Este texto é o resultado de uma entrevista realizada com os autores pelo Professor José Vicente Tavares dos Santos, responsável pela redação final, juntamente com os sociólogos Dani Rudniki e Carina Füsternau, em Porto Alegre, na primavera de 2003.

Jorge Luiz Paz Bengochea: Coronel da RR da Brigada Militar/RS. Autor dos livros "Policiamento Comunitário: como conquistar a confiança da Comunidade" e "Uma Nova Ordem na Segurança".

Luiz Brenner Guimarães: Coronel da RR da Brigada Militar/RS, Coordenador de Segurança Urbana da Secretaria Municipal de Direitos Humanos e Segurança Urbana da Prefeitura Municipal de Porto Alegre.

Martin Luiz Gomes: Ten. Cel. RR, Assessor de Pesquisa e Formação da Secretaria Municipal de Direitos Humanos e Segurança Urbana.

Sérgio Roberto de Abreu: Tenente Coronel da BMRS, Chefe do Estado Maior do Comando Regional do Litoral Norte do RS. 